\title{
Ostomi kapatılan hastalarda negatif basınçlı insizyon yönetim sistemi kullanımının etkinliği
}

\section{Efficiency of using negative pressure incision management system in patients with stoma closure}

\author{
Ramazan TOPCU* $\square$ İsmail SEZiKLi $\square$, Murat KENDiRCi $\square$, ibrahim Tayfun ŞAHINER $\square$
}

Hitit Üniversitesi Erol Olçok Eğitim ve Araştırma Hastanesi Genel Cerrahi ABD Çorum/TÜRKIYE

\section{Öz}

Amaç: Kolorektal cerrahide, son yıllarda özellikle stoma kapatıldıktan sonra insizyon yerinde yara iyileşmesi esnasında postoperatif komplikasyonları iyileştirmeye yönelik çalışmalar artmıştı. Özellikle cerrahi alan enfeksiyonları (CAE) ve yara ayrışması için negatif basınçlı insizyon kapama yöntemi (NBIKY) uygulamaları başlamıştır.

Çalışmalarda potansiyel olarak kontamine olma olasılığı yüksek yaralar üzerine uygulanan insizyonel negatif basınç uygulanması, CAE ve yara ayrışma gibi komplikasyonlar oranlarında azalma sağladığına dair veriler bulunmaktadır.

Bu çalışmada amaç, stoma kapatılması sonrası yara iyileşmesi esnasında postoperatif komplikasyonların üzerinde NBíKY'nin etkili olup olmadığını araştırmaktır.

Gereç ve Yöntemler: Ocak 2018- Aralık 2020 tarihleri arasında stoma kapatılması ameliyatı olmuş 64 hasta retrospektif olarak incelendi. Hastalar NBIKY uygulananlar ile konvansiyonel yara bakımı (KYB) yapılanlar olarak iki grupta incelendi.

Bulgular: Retrospektif olarak değerlendirilen 64 hastanın \%39,6'sına (n:25) NBIKY, \%60,4'üne (n:39) KYB uygulandı. Her iki grupta da en fazla kolorektal kanserlere bağlı stoma açıldığı görüldü. Her iki grup postoperatif yara yeri komplikasyonu olan CAE açısından karşılaştııılıı̆ında istatiksel olarak anlamlı fark saptandı (p: 0,032). 1.grupta 2 (\%8,0) 2.grupta 12 (\%30,8) hastada cerrahi alan enfeksiyonu görüldü. Yara ayrışması, evisserasyon, skar açısından her iki grup karşılaştııılığında istatiksel olarak anlamlı fark saptanmadı. Hastanede kalış süresi ve postoperatif insizyonel herni açısından karşılaştııılığında belirgin istatiksel anlamlıık görüldü (Sırasıyla p: 0,050 ve p: 0,018).

Sonuç: NBiKY uygulaması KYB ile karşılaştıııldığında kapatılan stoma insizyon yerinde belirgin olarak CAE, hastanede kalış, maliyet ve postoperatif herni oluşumunu azaltması konusunda üstün olduğu görülmektedir. Bu sonuçlar rutin uygulama açısından umut vericidir. Ancak bu çalışmaları destekleyecek büyük vaka sayıları olan randomize kontrollü prospektif çok merkezli çalışmalara ihtiyaç olduğunu düşünmekteyiz.

Anahtar Kelimeler: Stoma; Negatif basınçlı insizyon kapama yöntemi; Yara yeri enfeksiyonu.

Sorumlu Yazar*: Ramazan Topcu, Hitit Üniversitesi Erol Olçok Eğitim ve Araştırma Hastanesi Genel Cerrahi ABD Çorum/TÜRKIYE

E-posta: topcur58@gmail.com

ORCID: : 0000-0001-6214-4868

Gönderim: 13.07.2021 kabul: 20.09.2021

Doi: $10.18663 / \mathrm{tjcl} .971133$ 


\section{Abstract}

Aim: In colorectal surgery, studies have increased in recent years to improve postoperative complications during wound healing at the incision site, especially after stoma closure. Negative pressure incision closure method (NPICM) applications have started, especially for surgical site infections (SSi) and wound dehiscence.

Studies have shown that the application of negative incisional pressure on potentially contaminated wounds reduces the rate of complications such as surgical site infection and wound dehiscence.

The aim of this study is to investigate whether NPICM is effective on postoperative complications during wound healing after stoma closure.

Material and Methods: 64 patients who underwent stoma closure surgery between January 2018 and December 2020 were retrospectively analyzed. The patients were examined in two groups as those who underwent NPICM and those who received conventional wound care (CWC).

Results: Of the 64 retrospectively evaluated patients, 39.6\% (n:25) NPICM was performed, $60.4 \%$ ( $n: 39)$ underwent CWC. It was observed that stoma was opened mostly due to colorectal cancers in both groups. When both groups were compared in terms of SSI with postoperative wound complications, there was a statistically significant difference (p: 0.032). 2 in group $1(8.0 \%) 12$ in group 2 ( Surgical site infection was observed in $30.8 \%$ of the patients. No statistically significant difference was found between the two groups in terms of wound dehiscence, evisceration, and scarring. When the length of hospital stay and postoperative incisional hernia were compared, significant statistical significance was observed ( $p$ : 0.050 and p: 0.018 , respectively).

Conclusion: When NPICM application is compared with conventional wound care, it is seen that it is superior in reducing SSI, hospital stay, cost and postoperative hernia formation at the closed stoma incision site. These results are promising for routine application. However, we think that randomized controlled prospective multicenter studies with large case numbers are needed to support these studies.

Keywords: Stoma; Negative pressure incision closure method; Wound infection

\section{Giriş}

Geçici stoma açılması, mekanik intestinal obstruksiyon, distal rektum tümörleri, kolonik darlık, rektovajinal fistül, fekal peritonit, nekrotizan enterokolit, travmatik destrüktif kolon ve rektum yaralanlamaları, anastomoz kaçağı açısından riskli hastalar, travma ve sepsis nedeniyle hemodinamisi stabil olmayan hastalara yapılan bağırsağın cilde ağızlaştırılma işlemidir [1]. Geçici stomaları kapatmak için, altta yatan durum tamamen düzelmiş olması, hastanın genel sağlık durumunu tamamen düzelmesi, batın içi veya cilt altı var olan iltihap veya yapışıklıkların gerilemesi için en az 3-6 ay veya daha fazla süre geçmesi beklenir. Stoma kapatılmasının kendine ait çeşitli komplikasyonları vardır. Literatür incelendiğinde sadece stoma kapatılmasında dahi postoperatif morbidite \%0-40 gibi bir orana sahip olup, birçok komplikasyona da zemin hazırlamaktadır [2,3]. Cerrahi girişim sonrası yara komplikasyonları, karın ameliyatından sonra sık görülen bir durumdur ve cerrahi alan enfeksiyonunu (CAE), seroma, hematom oluşumu ve yara açılması gibi çeşitli istenmeyen klinik durumlara sebebiyet vermektedir. Cerrahi alan enfeksiyonları yalnızca ABD'deki tüm sağlık hizmetiyle ilişkili enfeksiyonların \% 36'sını oluşturmakta,
ABD'de 1.6 milyar \$ ek bir maliyete ve hastalarda 1000000 gün daha fazla hastanede kalışa neden olmaktadır [4,5]. Kolorektal cerrahi ameliyatın doğal kontamine doğası nedeniyle en yüksek CAE oranıyla ilişkilidir (s\%45)[6] . CAE'nun net sonuçları, hastanede kalma süresinin uzamasını, adjuvan tedavide gecikmeyi, insizyonel hernilerin potansiyel gelişimini, maliyetin artmasını ve nihayetinde hastanın yaşam kalitesinde bir düşüşü içermektedir $[7,8]$. CAE'nın nedeni, hastayla ilgili, çevresel ve cerrahi faktörler arasındaki etkileşimden kaynaklanan çok faktörlüdür. Bu nedenle, geleneksel bakım paketleri bu farklı bileşenleri hedeflemeyi amaçlar ve preoperatif antibiyotik profilaksisi ve aseptik cerrahi tekniğin kullanımını, intraoperatif normoterminin sürdürülmesini ve hasta risk faktörlerinin preoperatif optimizasyonunu içermektedir [9,10]. Bununla birlikte, bu önlemler CAE insidansını önemli ölçüde değiştirmede başarısız olmuştur $[9,11]$. Laparoskopik cerrahinin açık cerrahiye kıyasla önemli ölçüde daha düşük CAE insidansı ile sonuçlandığı gösterilmiştir $[12,13]$; ancak, tüm hastalar her zaman bu yaklaşım için uygun olmayabilir. Bu nedenle, açık cerrahi sonrası CAE gelişimini ortadan kaldırmak için yeni önleyici tedbirlere ihtiyaç vardır. 
Son yıllarda, kolorektal cerrahide, özellikle stoma kapatıldıktan sonra insizyon yerinde yara iyileşmesi esnasında postoperatif komplikasyonları iyileştirmeye yönelik çalışmalar artmıştır. Özellikle cerrahi alan enfeksiyonları ve yara ayrışması için negatif basınçlı insizyon kapama yöntemi (NBIKY) uygulamaları başlamıştır [14].

Çalışmalarda potansiyel olarak kontamine olma olasılığı yüksek yaralar üzerine uygulanan insizyonel negatif basınç uygulanması, cerrahi alan enfeksiyonu ve yara ayrışma gibi komplikasyonlar oranlarında azalma sağladığına dair veriler bulunmaktadır $[15,16]$.

Bu çalışmada amaç, stoma kapatılması sonrası yara iyileşmesi esnasında postoperatif komplikasyonların üzerinde NBIKY'nin etkili olup olmadığını araştırmaktır.

\section{Gereç ve Yöntemler}

Ocak 2018- Aralık 2020 tarihleri arasında stoma kapatılması ameliyatı olmuş 64 hasta retrospektif olarak incelendi. Hastalar NBIKY uygulananlar ile konvansiyonel yara bakımı (KYB) yapılanlar olarak iki grupta incelendi.

Retrospektif olarak değerlendirilip çalışmaya dâhil edilen hasta popülasyonunda; serviste ameliyat öncesi cilt hazırlığı (tüm vücut duşu ve ağız hijyeni), profilaktik antibiyotikler (metranidazol + seftriakson ) içeren standart bir cerrahi alan enfeksiyonu önleme protokolü olan hastalar tercih edildi. Tüm ameliyatlar, tüm konvansiyonel yara bakımları, tüm NBiKY uygulaması aynı cerrah tarafından yapılmıştır. Tüm stomalar ve yara yerleri aynı teknikle kapatılmış olup, postoperatif aynı antibiyotikler verilmiştir. Hastaların yaş, vücut kitle indeksi (BMI), hastane yatış süreleri, stoma tipleri ve açılma nedenleri, adjuvan kemoradyoterapi tedavi (KRT) alıp almadıkları, yapılan ameliyat, postoperatif lokal komplikasyonları, sigara kullanımı, sistemik hastalıkları, ilaç kullanımları ve maliyeti incelenmiştir.

\section{Stoma kapatma tekniği}

İleostomi ve loop kolostomi kapatma tekniği olarak; stoma etrafında çevresel bir kesi, intestinal halkanın serbest bırakılması, ostomi uçlarının cerrahi olarak eksizyonu ve elle $3 / 0$ vicrille çift kat üzerinden anastomoz yapılmıştır. Hartman kolostomi ise laparotomi sonrası uç kolostomi bozulması sonrası ya elle 3/0 Vicrille çift kat üzerinden anastomoz yada sirkuler stapler ile yapılmıştır.

\section{Yara kapama tekniği}

Fasya 1 numara loop PDS ile kapatıldıktan sonra ciltaltı doku bol serum fizyolojik ile yıkandı, daha sonra $3 / 0$ vicrille ciltaltı tek tek ve cilt polyprolen ile tek tek primer sütürlerle kapatıldı.

\section{Postoperatif lokal komplikasyonlar}

Yara yeri enfeksiyonu tanımlaması yara yerinden pürülan akıntı, enfeksiyon nedeniyle açık kalan yara uçları ve tedaviye dirençli seröz veya kanlı akıntı olan yara ve pozitif kültür olması olarak değerlendirildi. Yara ayrılması klinikte basit cilt ayrılması, evisserasyon ve evantrasyon olarak dâhil edildi. keloid ya da hipertrofik skar ve insizyonel herni olarak kayıt edildi.

\section{Negatif basınçlı insizyon kapama yöntemi}

Negatif basınçlı insizyon yönetim sistemi uygulanan gruptaki hastalarda kullanılan cihaz sistemi, yapışkan bir tabaka ile kaplı mikro delikli pansumanlı bir süngerden oluşmaktadır. Bu sistemde, süngere bir emme tahliyesi bağlanır ve sıvıları toplamak için küçük bir tank ile vakum uygulanır. Sistem devreye girdiğinde yaraya $125 \mathrm{~mm} \mathrm{Hg}$ negatif basınç uygulanır, varsa fazla sıvı alınır ve kesi dış kontaminasyondan tamamen izole edilir. Cihaz, ameliyattan hemen sonra (steril koşullar altında) yaraya uygulanır, 5-7 gün süreyle muhafaza edilir ve postoperatif yedinci günde cihaz çıkarılır.

\section{Konvansiyonel Yara bakımı}

Konvansiyonel yara pansumanı yapılan grupta ise ameliyattan hemen sonra (steril koşullar altında) yaraya içerisinde iyot içeren solusyon ile insizyon hattına uygulanır, steril gazlı bez ile üzeri kapatılır. 24 saat sonra yara açılarak nem buharı geçirgen spray sargı 5-7 gün uygulanır.

\section{Etik Onam}

Çalışma Helsinki Deklerasyonu kararlarına, hasta hakları yönetmeliğine ve etik kurallara uygun olarak planlandı. Çalışma öncesinde Hitit Üniversitesi Klinik Araştırmalar Etik Kurulundan onay alındı. (Karar no: 2020-312)

\section{İstatistiksel Analiz}

İstatistiksel analiz, Windows için SPSS yazılım versiyonu 18.0 (SPSS Inc, Chicago, Illinois) kullanılarak yapıldı. Sıralı değişkenler $\mathrm{X} 2$ testi kullanılarak analiz edildi, nominal değişkenler Fisher kesin testi ile analiz edildi ve istatistiksel anlamlılık için $\mathrm{P}<.05$ belirlendi.

\section{Bulgular}

Retrospektif olarak değerlendirilen 64 hastanın \%39,6'sına (n:25) NBIKY, \%60,4'üne (n:39) KYB uygulandı. Her iki grupta da en fazla kolorektal kanserlere bağlı stoma açıldığı görüldü (Tablo 1). Stomanın kapatılması incelendiğinde en çok her iki grupta da koruyucu loop ileostomi olduğu görüldü (Tablo 1). 


\begin{tabular}{|c|c|c|c|c|c|c|c|c|c|c|}
\hline \multicolumn{11}{|c|}{ Stoma açılma etiyolojisi } \\
\hline & RK & FAP & $\mathrm{KBI}$ & KBOI & AK & V & ASY & TK & $\mathrm{RP}$ & Total \\
\hline NBIKY & $13(\% 52)$ & $6(\% 24)$ & $2(\% 8)$ & $1(\% 4)$ & 0 & $1(\% 4)$ & 0 & $1(\% 4)$ & $1(\% 4)$ & 25 \\
\hline KYB & $14(\% 35,9)$ & $5(\% 12,8)$ & $11(\% 28,2)$ & $5(\% 12,8)$ & $2(\% 2)$ & 0 & $2(\% 5,1)$ & 0 & 0 & 39 \\
\hline Total & $27(\% 42,2)$ & $11(\% 17,2)$ & $13(\% 20,3)$ & $6(\% 9,4)$ & $2(\% 3,1)$ & $1(\% 1,6)$ & $2(\% 3,1)$ & $1(\% 1,6)$ & $1(\% 1,6)$ & 64 \\
\hline \multicolumn{11}{|c|}{$\begin{array}{l}\text { RK:Rektum kanseri, FAP:Familyal adenomatozis polipozis,KBi:Kansere bağlı ileus, KBOI:Kansere bağlı olmayan ileus } \\
\text { AK:Anastomoz kaçağı, KV:Kolonik Volvulus, ASY:Ateşli silah yaralanması, TK:Trafik kazası , RP:Rektum perforasyonu }\end{array}$} \\
\hline \multicolumn{11}{|c|}{ Kapatılan Stoma Tipleri } \\
\hline & \multicolumn{2}{|c|}{ Loop ileostomi } & \multicolumn{2}{|c|}{ Hartman kolostomi } & \multicolumn{3}{|c|}{ Loop Kolostomi } & \multicolumn{3}{|c|}{ Total } \\
\hline NBIKY & \multicolumn{2}{|c|}{21 (\%76) } & \multicolumn{2}{|c|}{$2(\% 8)$} & \multicolumn{3}{|c|}{$2(\% 8)$} & \multicolumn{3}{|c|}{25} \\
\hline KYB & \multicolumn{2}{|c|}{$27(\% 69,2)$} & \multicolumn{2}{|c|}{$7(\% 17,9)$} & \multicolumn{3}{|c|}{$5(\% 12,8)$} & \multicolumn{3}{|c|}{39} \\
\hline Total & \multicolumn{2}{|c|}{$48(\% 75)$} & \multicolumn{2}{|c|}{$9(\% 14,0)$} & \multicolumn{3}{|c|}{$7(\% 10,9)$} & \multicolumn{3}{|c|}{64} \\
\hline
\end{tabular}

Her iki grup cinsiyet, yaş, ek hastalık olup olmaması, KRT alması, sigara kullanımı ve BMı açısından karşılaştırıldığında istatiksel olarak anlamlı fark saptanmadı.(Tablo 2).

Her iki grup postoperatif yara yeri komplikasyonu olan CAE açısından karşılaştırıldığında istatiksel olarak anlamlı fark sapandı (p: 0,032).1.grupta $2(\% 8,0)$ 2.grupta $12(\% 30,8)$ hastada cerrahi alan enfeksiyonu görüldü. Yara ayrışması, evisserasyon, skar açısından her iki grup karşılaştırıldığında istatiksel olarak anlamlı fark saptanmadı. Hastanede kalış süresi ve postoperatif insizyonel herni açısından karşılaştırıldığında belirgin istatiksel anlamlılık görüldü (Sırasıyla p: 0,050 ve p: 0,018) (Tablo 2).

\begin{tabular}{|c|c|c|c|c|}
\hline & & $\begin{array}{l}\text { NBIKY (1.Grup) } \\
\text { N:25(\%39,6) }\end{array}$ & $\begin{array}{l}\text { KYB (2.Grup) } \\
\text { N:39(\%60,4) }\end{array}$ & $\begin{array}{l}\text { P Value } \\
\mathrm{P}<.05\end{array}$ \\
\hline Cinsiyet & $\begin{array}{l}\text { Erkek N(\%) } \\
\text { Kadın N(\%) }\end{array}$ & $\begin{array}{l}10(\% 40) \\
15(\% 60)\end{array}$ & $\begin{array}{l}17(\% 43,6) \\
22(\% 56,4)\end{array}$ & 0,777 \\
\hline Yaş & & $60,1 \pm 13,8$ & $67,4 \pm 15,2$ & 0,058 \\
\hline Ek hastalık & $\begin{array}{l}\operatorname{Var}(\%) \\
\text { Yok(\%) }\end{array}$ & $\begin{array}{c}9(\% 36) \\
16(\% 64)\end{array}$ & $\begin{array}{l}16(\% 41) \\
23(\% 59)\end{array}$ & 0,688 \\
\hline KRT & $\begin{array}{l}\operatorname{Var}(\%) \\
\text { Yok(\%) }\end{array}$ & $\begin{array}{l}10(\% 40) \\
15(\% 60)\end{array}$ & $\begin{array}{l}15(\% 38,5) \\
24(\% 61,5)\end{array}$ & 0,902 \\
\hline $\mathrm{BMI}$ & & $25,3(18,3-28,3)$ & $25,3(18,3-44,8)$ & 0,098 \\
\hline Sigara & $\operatorname{Var}(\%)$ & $8(\% 32,0)$ & $19(\% 48,7)$ & 0,186 \\
\hline CAE var(\%) & & $2(\% 8,0)$ & $12(\% 30,8)$ & 0,032 \\
\hline Yara ayrısma & $\operatorname{Var}(\%)$ & 0 & $4(\% 10,3)$ & 0,149 \\
\hline Eviserasyon & $\operatorname{Var}(\%)$ & 0 & $2(\% 5,1)$ & 0,516 \\
\hline Herni & $\operatorname{Var}(\%)$ & 0 & $8(\% 20,5)$ & 0,018 \\
\hline Skar & $\operatorname{Var}(\%)$ & 0 & $3(\% 7,7)$ & 0,275 \\
\hline Yatış süresi & & $7,0(5,0-12,0)$ & $7,0(6,0-30,0)$ & 0,050 \\
\hline
\end{tabular}

\section{Tartışma}

$\mathrm{CAE}$, stoma kapatılmasından sonra önemli ve yaygın bir komplikasyondur. Peristomal cildin önemli sayıda enterik bakteri barındırdığı bildirilmektedir ve prosedür aynı zamanda enterik anastomozu da gerektirdiğinden, stoma kapatılması temiz-kontamine bir prosedür olarak kabul edilir [17]. Ameliyat sonrası hastanede kalış süresinin uzamasına, ayakta tedavi başvurularının artmasına, evde ek sağlık hizmeti kullanımına ve tıbbi maliyetlerin artmasına neden olur. Ayrıca stoma kapanması sonrası CAE'nin geç bir komplikasyonu olarak abdominal insizyonel herni gelişebilir. Karın kesi fıtığı, hastanın yaşam kalitesini önemli ölçüde azaltabilir ve yeniden ameliyat gerektirebilir. Bu nedenle tıbbi maliyetlerde daha fazla artışa yol açar.

NBIKY, yara yüzeyinin otomatik olarak temizlenmesi ve çözünen cansız doku ve eksüdanın erken ve agresif bir şekilde çıkarılması yoluyla bakteri üremesini önleyebilir. Stoma kapanma yarasında NBIKKY kullanıldığında, granülasyonun teşvik edilmesi ölü boşluğu ve CAE riskini azaltabilir ve böylece yara iyileşme süresini kısaltabilir. Bu, sağlık personeli ve hastalar 
üzerindeki yükü azaltacak ve yatan hasta sürelerinde, ayakta tedavi ziyaretlerinde ve maliyette azalmaya yol açacaktır [1824]. Bu çalışmada cerrahi alan enfeksiyonu NBIKKY uygulanan hastalarda KYB uygulananlara göre istatiksel olarak anlamlı idi ve bariz şekilde CAE 'da azalma olduğu görüldü. Bu çalışmaya benzer iki çalışmada, NBIKY'nin ileostomi kapanma bölgelerine uygulanmasını değerlendirmişler ve NBIKY'nin CAE oranını azaltmadaki etkinliğini göstermişler $[25,26]$. Yani literatürdeki mevcut çalışmalar bizim çalışmamızı desteklemektedir.

Literatürden elde edilen veriler, NBIKY kullanırken CAE oranlarında büyük farklılıklar gösterir. Cantero et al. Çift döngü ileostominin geri döndürülmesinden sonra \%0'lık bir CAE oranı bildirmiştir [25]. Ancak bu çalışmada yaraya 7 gün süreyle NBIKY uygulanmış ve farklı bir yara kapama tekniği (zımba) uygulanmıştır. Bir kohort çalışmada KYB kullanırken \%21'lik CAE oranlarından bahsetmişlerdir.

Semsarzadeh ve meslektaşlarının bir meta-analizi, NBIKY kullanılanlarda abdominal cerrahi sonrası CAE oranlarını $\% 0$ (sezaryen; KYB ile \%8.3) ile \%20,4 (ventral fıtık; KYB ile \%25.8) arasında göstermiştir [27]. Li ve ark. abdominal cerrahi geçiren hastalarda CAE oranlarını \%4 (NBIKY) ile \%31 (KYB; $p=0.028$ ) olarak bildirmiştir [28]. Blackham ve ark. abdominal karsinom nedeniyle ameliyat edilen hastalarda CAE oranlarını \%6,7 (NBIKY) ile \%17,2 (KYB) ( $p=0,035$ ) olarak açıklamışlardır [29]. Bu çalışmada ise CAE oranları \% 8 (NBIKY) ile \% 30,2 (KYB) idi. Mevcut olan çalışmalarla uyumlu idi.

Bu çalışmada, NBIKY ile tedavi edilen hastaların hastanede kalış süresinin istatiksel olarak anlamlı olmasının nedeni azalmış CAE oranı ile ilişkilendirilebilir. CAE azalmasına bağlı olarak postoperatif insizyonel herni, hastanede kalış ve maliyette de azalma olduğu tespit edilmiştir. Her iki grupta da herni ve hastanede kalış açısından istatiksel olarak anlamlı fark bulunmuştur. Ayrıca bu çalışmada KYB olan grupta CAE olan hastaların 6'sında 1 yıl sonraki takiplerinde kesi yeri fıtığı geliştiği görüldü. Genel olarak bakıldığında CAE'na bağlı olarak hem hastanede yatış hem de buna bağlı gelişen fıtıklar ve tekrar bir operasyon düşünüldüğünde maliyetin artacağı aşikârdır. Zaten CAE olması durumunda uzun süreli hastanede kalış ve artan tedavi maliyetleri açısından önemli bir ekonomik yük ile ilişkili olduğu gösterilmiştir [5].

Retrospektif bir çalışma olması nedeniyle maliyet analizi yapmak açısından zorlukla karşılaşıldı, NBYT'nin maliyetinin daha yüksek olabileceği konusunda bir önyargı olsa da bu yaklaşımla yönetilen hasta grubunda gerek hastane yatış sürelerinin daha kısa olması, gerek daha nadir pansuman değişimi nedeniyle ve bu anlamda daha az sağlık personeli işgücü gerektirmesi, gerekse komplikasyon oranlarının daha az olması ve bunların yönetimi için gerekli maliyetinde düşünülmesi durumunda detaylı maliyet analizinin prospektif bir çalışma ile daha net ortaya konulabilir.

\section{Sonuç}

NBIKY uygulaması konvansiyel yara bakımı ile karşılaştırıldığında kapatılan stoma insizyon yerinde belirgin olarak $C A E$, hastanede kalış, maliyet ve postoperatif herni oluşumunu azaltması konusunda üstün olduğu görülmektedir. Bu sonuçlar rutin uygulama açısından umut vericidir. Ancak bu çalışmaları destekleyecek büyük vaka sayıları olan randomize kontrollü prospektif çok merkezli çalışmalara ihtiyaç olduğunu düşünmekteyiz.

\section{Maddi destek ve çıkar ilişkisi}

Çalışmayı maddi olarak destekleyen kişi/kuruluş yoktur ve yazarların herhangi bir çıkara dayalı ilişkisi yoktur.

\section{Kaynaklar}

1. Klink $C D$, Wunschmann $M$, Binnebosel $M$, et al. Influence of skin closure technique on surgical site infection after loop ileostomy reversal: retrospective cohort study. Int J Surg. 2013; 11: 1123-5.

2. Milanchi S, NasseriY, KidnerT, et al. Wound infection after ileostomy closure can be eliminated by circumferential subcuticular wound approximation. Dis Colon Rectum. 2009; 52: 469-74.

3. Vermulst N, Vermeulen J, Hazebroek EJ, et al. Primary closure of the skin after stoma closure-management of wound infections is easy without (long-term) complications. Digest Surg. 2006; 23: 255-8.

4. Zimlichman E, Henderson D, Tamir O, et al. Health care-associated infections: a meta-analysis of costs and financial impact on the US health care system. JAMA Intern Med. 2013; 173.

5. de Lissovoy G, Fraeman K, Hutchins V,et al. Surgical site infection: incidence and impact on hospital utilization and treatment costs. Am J Infect Control. 2009; 37 :387-97.

6. Wick EC, Vogel JD, Church JM, et al. Surgical site infections in a "high outlier" institution: are colorectal surgeons to blame? Dis Colon Rectum. 2009; 52 :374-9.

7. Gheorghe A, Moran G, Duffy $\mathrm{H}$,et al. Health utility values associated with surgical site infection: a systematic review. Value Health. 2015; $18: 1126-37$.

8. Murray BW, Cipher DJ, Pham T, et al. The impact of surgical site infection on the development of incisional hernia and small bowel obstruction in colorectal surgery. Am J Surg. 2011; 202 :558-60. 
9. Anthony T, Murray BW, Sum-Ping JT, et al. Evaluating an evidence-based bundle for preventing surgical site infection: a randomized trial. Arch Surg. 2011; 146 :263-9.

10. Ploegmakers IB, Olde Damink SW, et al. Alternatives to antibiotics for prevention of surgical infection. Br J Surg. 2017; 104: 24-33.

11. Pastor $C$, Artinyan $A$, Varma MG,et al. An increase in compliance with the Surgical Care Improvement Project measures does not prevent surgical site infection in colorectal surgery. Dis Colon Rectum. 2010; 53 :24-30.

12. Aimaq R, Akopian G, Kaufman HS. Surgical site infection rates in laparoscopic versus open colorectal surgery. Am Surg. 2011;77:1290-4.

13. Schwenk W, Haase O, Neudecker J,et al. Short term benefits for laparoscopic colorectal resection. Cochrane Database Syst Rev. 2005.

14. Argenta LC, Morykwas MJ. Vacuum-assisted closure: a new method for wound control and treatment: clinical experience. Ann Plast Surg 1997; 38: 563-76.

15. Strugala V, Martin R. Meta-Analysis of Comparative Trials Evaluating a Prophylactic Single-Use Negative Pressure Wound Therapy System for the Prevention of Surgical Site Complications. Surg Infect (Larchmt). 2017; 18 :810-9.

16. O'Leary DP, Peirce C, Anglim B, et al. Prophylactic Negative Pressure Dressing Use in Closed Laparotomy Wounds Following Abdominal Operations: A Randomized, Controlled, Open-label Trial: The P.I.C.O. Trial. Ann Surg. 2017; 265: 1082-6.

17. Pemmaraju VT, Lansing SS, Husain S. A protocol for skin closure after stoma reversal. Tech Coloproctol. 2020; 24: 255-7.

18. Fernandez R, Griffiths R. Water for wound cleansing. Cochrane Database Syst Rev. 2008.

19. Wackenfors A, Gustafsson R, Sjogren J, et al. Blood flow responses in the peristernal thoracic wall during vacuum-assisted closure therapy. Ann Thorac Surg. 2005; 79: 1724-31.

20. Morykwas MJ, Argenta LC, Shelton-Brown El,et al. Vacuumassisted closure: a new method for wound control and treatment: animal studies and basic foundation. Ann Plast Surg. 1997; 38: 553-62.
21. Wackenfors A, Sjogren J, Gustafsson R, et al. Effects of vacu-massisted closure therapy on inguinal wound edge microvascular blood flow.Wound Repair Regen. 2004; 12: 600-6.

22. Brinkert D, Ali M, Naud M, et al. Negative pressure wound therapy with saline instillation: 131 patient case series. Int Wound J. 2013; 10: 56-60.

23. Fluieraru S, Bekara $F$, Naud $M$, et al. Sterile-water negative pressure instillation therapy for complex wounds and NPWT failures. J Wound Care. 2013; 22: 293-9.

24. Gupta S, Gabriel A, Lantis J, Téot L. Clinical recommendations and practical guide for negative pressure wound therapy with instillation. Int Wound J. 2016; 13: 159-74.

25. Cantero R, Rubio-Perez I, Leon M, et al. Negative-pressure therapy to reduce the risk of wound infection following diverting loop ileostomy reversal: an initial study. Adv Skin Wound Care. 2016; 29: 114-8.

26. Poehnert D, Hadeler N, Schrem H, et al. Decreased superficial surgical site infections, shortened hospital stay, and improved quality of life due to incisional negative pressure wound therapy after reversal of double loop ileostomy. Wound Repair Regen. 2017; 25: 994-1001.

27. Semsarzadeh NN, Tadisina KK, Maddox J, et al. Closed incision negative-pressure therapy is associated with decreased surgicalsite infections: a meta-analysis. Plast Reconstr Surg 2015; 136 : $592-602$

28. Li PY, Yang D, Liu D, et al. Reducing surgical site infection with negative-pressure wound therapy after open abdominal surgery: a prospective randomized controlled study. Scand J Surg 2017; 106: 189- 95.

29. Blackham AU, Farrah JP, McCoy TP, et al. Prevention of surgical site infections in high-risk patients with laparotomy incisions using negative-pressure therapy. Am J Surg 2013; 205 : 647- 54. 